\title{
Evolution of auditor's report in the focus of sustainable development of socio-economic systems
}

\author{
Bibigul Amanzholova ${ }^{1}$, Elena Khomenko ${ }^{1}$, Alina Imansakipova ${ }^{2}$, and Aisulu Kulekeshova ${ }^{3}$ \\ ${ }^{1}$ Novosibirsk State Technical University, Karla Marksa Str., 20, 630073 Novosibirsk, Russia \\ ${ }^{2}$ Lomonosov Moscow State University, Leninskiye Gory Str., 1, 119991 Moscow, Russia \\ ${ }^{3}$ S.Seifullin Kazakh Agrotechnical University, Zhenis ave., 62, 010011 Nur-Sultan, Kazakhstan
}

\begin{abstract}
The article presents two focuses on the study of the evolution of the audit report. The first is the study of the audit report as an indicator characterizing the sustainability of such a socio-economic system as audit. The second is the study of the audit report as a factor contributing to the growth of trust and increase the information value of reporting for the sustainable development of both separate economic entities and socioeconomic systems. The authors established a framework for the functioning of audit as a socio-economic system, which allowed assess the sustainability of this system in dynamics. Based on the analysis of statistical information the authors formulated the proposals on some key matters of the Russian audit. The first is the necessity to clarify the subject and scope of audit activities, taking into account the current needs of audit services consumers and analysis of practice. The second is the possibility of expanding the format of the audit report on the financial statements for different groups of audited entities. The third is the expansion of the practice of performing the audit engagements on non-financial reporting. The authors recognized the evolution of standards, but at the same time, they raised the question of the need to study the effects of changes in the regulation of the audit report. The authors' approach to the audit report investigation launched the prospects for further research. They covers analysis of the contradictions between the audited entity requirements and stakeholders requirements for the audit report; and assessment of the impact of audit report under the standard form on the satisfaction of various groups of the financial statements users, taking into account the considerable differences and contradictions in their requirements.
\end{abstract}

\section{Why are we discussing the auditor's report?}

The recent history of Russian audit goes back 30 years. This period, on the one hand, is associated with the intensive development of the profession and the market, but, on the other hand, in this period there were sharp changes in the regulatory model. The above characteristics indicate the absence of a strategic context in determining policies and making individual decisions related to the development of the market and profession.

At the end of 2019, the Ministry of Finance of the Russian Federation approved a 
document that for the first time in a long period defined the concept or directions of audit activity development (Order of the Ministry of Finance of the Russian Federation (2019). This document determines that the purpose of audit activity at the present stage is generating and maintaining the confidence of the business community and society in the results of audit services providing. It is important to note that such a target agree completely with the concept of the International Standards on Auditing (ISA) system, applied in Russia since January 1, 2017. However, the question of harmony in the ISA targets and audit practices developed over 30 years is still crucial. Therewith, we consider the practice in a broad sense as institutions, legal norms, traditions of law enforcement, the culture of audit results using in socio-economic systems management.

Thus, the authors agree with the opinion of audit services consumers that the imperfection of the system of legal and other regulatory acts, including the instability of legislation on audit activity, and inconsistency of certain norms affect adversely the state and development of the audit institution. We share the view that the tendency of excessive formalization of audit activity rules contradicts the nature of this activity. As a result, such a formalization is capable of discrediting both the audit institution and the professional opinion of the auditor on reporting.

The authors systematized the arguments in favor of the need to study issues related to the audit report, which determined the hypotheses put forward in the research.

Firstly, the auditor's opinion on the reliability of reporting reflected in the audit report, leads and may lead to a variety of socio-economic effects for various groups of stakeholders. That is why the formation of such an opinion should be in the nature of a dialogue of auditors with real and potential users of reporting. According to the authors, the external environment where auditors and audited entities operate determines the context of such a dialogue. The audit standards set a framework of this dialog, while needs and expectations of reporting users set its focal points.

Secondly, there is a high degree of development of audit tools and a fragmented study of the audit report functions, which are beyond the traditional confirmation of the reliability of reporting. Specifically, it is necessary to study issues of influence or potential impact of the information contained in the audit report on the prospects for the audited entity activities. In addition, the focus on sustainable development, which led to the transformation of various levels socio-economic systems in accordance with the goals of sustainable development, on the one hand, expands the flexibility/freedom of the auditor, but, on the other hand, it requires the auditor a new quality of responsibility as a full participant in the dialogue with stakeholders. In turn, it requires new methods and tools applicable to new audit subject areas.

Thirdly, we may recognize the solution of methodical problems that require an interdisciplinary approach, such as judgement of materiality and components of audit risk, planning an audit sampling, analysis of the selective test results, applying quantitative and qualitative analytical procedures in judgement of company's ability to continue as a going concern. In such studies, statistical methods and economic-mathematical modeling are widely used, that significantly enriches the audit tools and lays the groundwork for analyzing its adequacy to the tasks solved. However, when it comes to the audit report, the factors of modification of the auditor's opinion, their relationship with the materiality threshold, with the criteria of audit evidences sufficiency and satisfactory are the most often subjects of scientific and applied research. The authors believe that the issues of professional behavior, professional skepticism require interdisciplinary research at the intersection of sociology, psychology, behavioral economics and finance.

Thus, in the article, the authors bring up two questions for discussion. The first question is if we are noticing the audit report evolution. It is about evolution not only in a narrow sense - as a document containing an opinion on reporting, but also in a broad sense - as an 
opinion and conclusions, often focusing on significant, problematic aspects or prospects of a client's activities. The second question is if we have reason to say that the evolution of the audit report is a reaction of the profession to the adoption of a sustainable development paradigm. In other words, do changes in approaches to regulation and the formation of an audit report lay in the context of socio-economic systems sustainable development?

\section{Audit as a socio-economic system}

We consider the following aspects to be crucial in applying approaches to investigation of the socio-economic systems sustainability. First, it is important to determine the scope of socio-economic systems study: global, national, regional or other local framework.

Secondly, it is important to determine the composition of the socio-economic system and the hierarchy of its elements. Thirdly, it is necessary to choose an approach to measuring the socio-economic systems sustainability. It is possible to decide on a set of indicators reflecting certain aspects of sustainable development including social, economic, institutional and environmental ones. The second option is using an integrated indicator to assess the sustainability of socio-economic development.

What concerns auditing as an industry, today the role of the global framework is strengthening (in particular, international standardization), and the national framework is always applicable to Russian conditions in terms of the impact of state regulation and selfregulation.

Let us illustrate the influence of the national framework on the research of the sustainability of the auditing industry as a socio-economic system.

Currently, most of the entities involved in the circle of audit activity in Russia agree on the low level of demand on audit services of high quality. The authors of the article are likely to share this opinion, since the results of the analysis of statistical information over the series of years confirm this conclusion.

In our opinion, the low demand appears not only in the worsening of the audit market indicators, but also in significant changes in the parameters of scale of the profession. These parameters include the number of auditors and the number of audit organizations. According to the Ministry of Finance of the Russian Federation, the number of audit organizations accounted for 4.7 thousand units as of December 31, 2018. It decreased by 1.5 thousand units compared to 2011 (6.2 thousand units as of December 31, 2011). However, decrease of the number of auditors give more rise to concern.

The authors believe that such dynamics is a reaction of the profession to "gross changes" in the system of state and professional regulation of audit activity, as well as to structural changes in the economy, including in sectors and segments of the economy with a high share of mandatory audit.

We revealed the downward trend in the share of initiative audit from $16.7 \%$ in 2013 to $8.6 \%$ in 2018 that is the first argument.

It is important to note that the organizations whose financial indicators (income and total assets) are higher than the minimum values as well as joint-stock companies dominate in mandatory audit segment ( $48.8 \%$ and $31.1 \%$ in 2018 respectively). At the same time, the share of joint-stock companies was $19.9 \%$ in 2015 and $35 \%$ in 2016 . There were changes in civil law, which gave rise to the need for re-registration of closed joint-stock companies in joint-stock companies or public companies. It was the main reason of the growth.

The underestimation of audit services value by economic entities, owners and investors is the bottom of this situation. In other words, the audit report does not fulfill its main functions, which is in the formation and maintenance of the confidence of the business community and society in financial reporting.

The introduction of a mandatory audit without reference to needs of financial reporting 
users is one of the reasons for this situation too. Arguing for this position, the authors cited statistics on mandatory audit by the criterion of exceeding financial indicators, which has not relevant to providing the attractiveness of the organization by demonstrating transparency of financial condition and financial performance.

We do not share the opinion that the main factor determining the demand on audit services is the level of financial solvency (often insolvency) of real and potential audited entities. We suppose that a focus on information disclosure and transparency boost investment attractiveness, provide access to long-term and short-term financing sources, and lay grounds for setting up joint ventures and joint projects.

That is why in order to ensure the sustainability of audit as a necessary element of economic and social systems, and as a condition for achieving a balance of interests of most subjects of such systems, it is important to review some key positions of national audit. Let us highlight some of them directly related to the audit report.

First of all the subject and scope of audit activity require clarification proceeding from the current needs of audit services consumers and the analysis of audit practice. At the same time, it is important to explore the possibility of an expanded format for the audit report for different groups of audited entities.

In addition, it is important to decide on the expansion of the practice of performing assurance engagement on non-financial reporting and other information. In other words, it is necessary to measure the effects of verification and publication of non-financial reporting.

The following illustration regards to generalization of the results of external audit quality control by the self-regulatory organization (SRO). According to quality control results published periodically by the Ministry of Finance of the Russian Federation violations of requirements to the main elements, form, content, procedure of the audit report signing and presenting classified as typical violations and occur in all reports from 2011 to 2018. In this case, we may recognize a systemic problem of non-compliance by auditors with audit standards in their professional activities. It could be, for example, due to the speed of adaptation to changes in regulatory, which influence the quality of methodical solutions and tools developing and applying by audit organizations.

When changing audit regulation models, legislative acts, including standards on auditing, Russian auditors and audit organizations were appealed for developing and improving not only audit methods and procedures, but also analytical tools for summarizing the results. Over more than 20 years, standards of four generations regulated the aspects of activities related to the audit report. Certainly, it is rightfully to recognize the change of generations of standards as evolutionary. Four standards regulate the auditor's report at present. It prove detailing the requirements in accordance with the needs or expectations of users of financial reporting and auditor's reports. In authors' opinion, the ISA 701 "Communicating Key Audit Matters in the Independent Auditor's Report" needs special attention.

We studied the auditor's reports of public companies, which, due to the specifics of their activities, are required to demonstrate openness, and confirmed the increase in the information value of the report by communicating key audit matters. So, in the auditor's report of Raspadskaya PJSC for 2017-2019 the key mentioned matters are, firstly, the assessment of the long-term financial investments, the proportion of which ranged from 47 $\%$ to $33 \%$ in total assets, and secondly, the assessment of land restoration obligations.

The specificity of audit procedures focused on the analysis of accounting estimates and their disclosure in reporting determines the assessment of financial investments. The auditor's report on the statements has been including an assessment of the land restoration obligation since 2018. This fact prompts to ask questions to the auditors. Explaining the reason for communicating this key matter, they note the scope of activity - mining, as well 
as related obligations to restore disturbed lands. However, in 2017, the organization conducted the same activity, but the share of accounting estimates in total balance did not exceed $2 \%$.

In our opinion, these facts demonstrate that, when making decisions on audited statements, they supplement the assumptions of the reporting reliability by new criteria and factors based on the needs of reporting users. However, it is important to understand which effects appear or may appear following the revision of audit methods and tools in pursuit of compliance with standards. There may be a situation where the costs for adapting to changes will not be comparable with the effects of the audit reports in the conditions of prevailing of mandatory audit in Russia. Therefore, the subject of the research should and may be the factors that influence the opinion of the auditor in the auditor's report. At the same time, it is important to reveal not only the factors determining the reasonable assurance and professional behavior of the auditor, but also the factors associated with the audited entity and its environment.

The analysis of studies presented in Scopus confirm the above. When choosing the studies for the review, we proceeded from the capacity of the database and the representativeness of the sample used by foreign authors, as well as the nature of the information processing methods - multivariate testing with the use of a logistic model. Following the results of the review, we identified factors influencing audit report according to the researchers.

Thus, Jean Bedard, Carl Brousseau and Ann Vanstraelen (2018) found that disclosing in an additional paragraph of the audit report information about doubts on the prospects of the audited entity's activity is of particular importance to investors. Therefore, when deciding on a qualification, it is necessary to take into account the expectations of investors. According to Sanoran Kanyarat (2018), professional skepticism and conservatism of auditors is more likely during the financial crisis compared to the post-crisis period. The author made such a conclusion from the audit reports of 883 US companies, which for the first time received an audit report with doubt about the going concern, and 537 bankrupt companies. This approach to sampling provided reliable results of the study.

Thomas C. Omer, Nathan Y. Sharp and Dechun Wang (2018) concluded that audit companies with offices located in regions under significant religious influences are more likely to modify opinions. Characteristics of the auditor such as specialization, duration of employment, education, marital status and other factors have a significant impact on the modification of the audit opinion.

Mohammad Noor Hisham Osman, Zaidi Mat Daud, Ahmed Razman Abdul Latiff and Zulkarnain Muhamad Sori (2018) found it when investigated the audit reports on the financial statements of 644 Malaysian public companies that made a significant contribution to the development of the country's economy.

The studies of Linda A. Myers, Jonathan E. Shipman, Quinn T. Swanquist and Robert L. Whited (2018), Feng Chen, Kevin Lam, Wally Smieliauskas and Minlei Ye (2016) proved that there is a "delay" in the audit report in comparison with market reactions and the uncertainty of the assets valuation. It takes place due to the period between the audit report issuing and the end of the financial year.

In our opinion, such studies confirm the relevance of investigating the relationship between various factors and the audit report characteristics, as well as emphasize the importance of the study of factors that may influence the professional behavior of auditors. Such a research agenda indicates the dynamics of users' expectations regarding the audit report, which, in turn, give evidence of the evolution of the audit report. We mean the audit report in a broad sense as a qualified opinion, expert assessment, reasonable conclusions that contribute to the growth of trust and increase the information value of reporting. 


\section{Results}

Thus, it is necessary to consider the audit report on two sides. In a narrow sense, it is an official document, in which auditors express their opinion on the reliability or other characteristics of the financial statements. In a broad sense, we consider the audit report in three planes.

Firstly, the information included in the audit report characterizes the results of the audited entity management activity on ensuring the financial statements quality. Secondly, the audit report prove the quality of the auditors' activities on the audit procedures performing and the generalization of their results regarding certain financial statements.

Thirdly, the audit report has the potential to formulate needs and expectations of the financial statements users, as well as to assess their satisfaction.

This approach, combining the types of auditor's report, legal prerequisites and expectations of users of the financial statements as research parameters, allows significantly shift the focus of scientific research in this area. The new approach will provide a transition from the study of factors modifying the opinion of the auditor, and the relationship between reliability and materiality to the research of the satisfaction of real and potential users of financial statements and the audit report.

That way, the satisfaction of potential users of the reporting with the audit report is one of the most urgent audit issues. This circumstance defines the following prospects for further research:

- analysis of the contradictions between the audited entity requirements and stakeholders requirements for the audit report;

- assessment of the impact of audit report under the standard form on the satisfaction of various groups of the financial statements users, taking into account the considerable differences in their requirements.

\section{References}

1. F. Chen, K. Lam, W. Smieliauskas, M. Ye, International Journal of Auditing, 20, 52 (2016)

2. J. Bédard, C. Brousseau, A. Vanstraelen, A Journal of Practice \& Theory, 38, 27 (2019)

3. L. A. Myers, J. E. Shipman, Q. T. Swanquist, R. L. Whited, Review of Accounting Studies, 23, 1512 (2018)

4. M. Noor, H. Osman, Z. M. Daud, A. Razman, A. L. Zulkarnain, M. Sori, International Journal of Economics and Management, 12(2), 671 (2018)

5. Official website of the Ministry of Finance of the Russian Federation. http://www.minfin.ru/

6. Order of the Ministry of Finance of the Russian Federation of 29.11.2019 (1592). http://www.consultant.ru/

7. Official website of the PAO Raspadskaya. Information Disclosure. http://www.raspadskaya.ru/

8. S. Kanyarat, Journal of Contemporary Accounting and Economics, 14, 164 (2018)

9. T. C. Omer, N. Y. Sharp, D. Wang, Journal of Business Ethics, 149, 811 (2018) 